This document was prepared in conjunction with work accomplished under Contract No. DE-AC09-96SR18500 with the U.S. Department of Energy.

This work was prepared under an agreement with and funded by the U.S. Government. Neither the U. S. Government or its employees, nor any of its contractors, subcontractors or their employees, makes any express or implied: 1 . warranty or assumes any legal liability for the accuracy, completeness, or for the use or results of such use of any information, product, or process disclosed; or 2 . representation that such use or results of such use would not infringe privately owned rights; or 3 . endorsement or recommendation of any specifically identified commercial product, process, or service. Any views and opinions of authors expressed in this work do not necessarily state or reflect those of the United States Government, or its contractors, or subcontractors. 
WSRC-STI-2007-00009

This paper is proposed for the publication and presentation in $5^{\text {th }}$ Joint ASME/JSME Fluids Engineering Conference, July 30 - August 2, 2007, San Diego, CA, USA.

\title{
Applications of CFD Method to Gas Mixing Analysis in a Large-Scaled Tank
}

\author{
S. Y. Lee* and R. A. Dimenna \\ Computational and Statistical Science Dept. \\ Savannah River National Laboratory \\ Washington Savannah River Company \\ Aiken, SC 29808 \\ *Phone: (803) 725-8462; (803) 725-8203
}

\begin{abstract}
The computational fluid dynamics (CFD) modeling technique was applied to the estimation of maximum benzene concentration for the vapor space inside a large-scaled and high-level radioactive waste tank at Savannah River site (SRS). The objective of the work was to perform the calculations for the benzene mixing behavior in the vapor space of Tank 48 and its impact on the local concentration of benzene. The calculations were used to evaluate the degree to which purge air mixes with benzene evolving from the liquid surface and its ability to prevent an unacceptable concentration of benzene from forming.

The analysis was focused on changing the tank operating conditions to establish internal recirculation and changing the benzene evolution rate from the liquid surface. The model used a three-dimensional momentum coupled with multi-species transport. The calculations included potential operating conditions for air inlet and exhaust flows, recirculation flow rate, and benzene evolution rate with prototypic tank geometry. The flow conditions are assumed to be fully turbulent since Reynolds numbers for typical operating conditions are in the range of 20,000 to 70,000 based on the inlet conditions of the air purge system. A standard two-equation turbulence model was used.
\end{abstract}

The modeling results for the typical gas mixing problems available in the literature were compared and verified through comparisons with the test results. The benchmarking results showed that the predictions are in good agreement with the analytical solutions and literature data. Additional sensitivity calculations included a reduced benzene evolution rate, reduced air inlet and exhaust flow, and forced internal recirculation.

The modeling results showed that the vapor space was fairly well mixed and that benzene concentrations were relatively low when forced recirculation and $72 \mathrm{cfm}$ ventilation air through the tank boundary were imposed. For the same $72 \mathrm{cfm}$ air inlet flow but without forced recirculation, the heavier benzene gas was stratified. The results demonstrated that benzene concentrations were relatively low for typical operating configurations and conditions. Detailed results and the cases considered in the calculations will be discussed here. 


$\begin{array}{ll}\text { Nomenclature } \\ \mathrm{C}_{0}, C_{\mu} \text { constants } \\ \mathrm{D} & \text { diameter } \\ d_{0} & \text { nozzle diameter } \\ \mathrm{H} & \text { height } \\ \mathrm{ft} & \text { foot }(0.3048 \mathrm{~m}) \\ \mathrm{g} & \text { gravitational acceleration } \\ \mathrm{cfm} & \mathrm{ft}^{3} \text { per minute } \\ k & \text { turbulent kinetic energy } \\ \text { in } & \text { inch (0.0254 m) } \\ \mathrm{LFL} & \text { Lower flammability limit } \\ \mathrm{p} & \text { pressure } \\ \mathrm{sec} & \text { seconds } \\ \mathrm{SG} & \text { specific gravity } \\ \mathrm{t} & \text { time } \\ v(x) & \text { local velocity at point } x \\ x & \text { axial distance from nozzle } \\ \varepsilon & \text { rate of dissipation of turbulent kinetic energy } \\ \eta & \text { nondimensional axial distance from nozzle } \\ \mu & \text { dynamic viscosity } \\ \rho & \text { density } \\ \end{array}$




\section{Introduction}

Savannah River Site (SRS) has been evaluating flammability conditions of benzene gas in the vapor space of Tank 48 in association with the safety analysis. In order to help assess the benzene concentration in the vapor space, a computational model has been developed to estimate the degree of benzene mixing for nominal conditions of purging airflow and benzene since airflow behavior is similar to the actual purging gas of nitrogen. The geometrical configurations for the tank vapor space are shown in Fig. 1.

A computational fluid dynamics (CFD) method was applied for the evaluation of air flow patterns and quantitative estimate of local benzene concentration in the vapor space. The modeling domain represents the major features of the Tank 48 and includes the principal air flow ventilation path of the Tank 48 vapor space. The tank vapor space is about $29 \mathrm{ft}$ height and $85 \mathrm{ft}$ diameter. It is occupied by the 82-in concrete support column as the center of the tank as shown in Fig. 1.

The objective of the work is to evaluate the benzene mixing behavior in the vapor space of Tank 48 and its impact on the local concentration of benzene inside the tank. The calculations will be used to evaluate the degree to which purge air mixes with benzene evolving from the liquid surface and its ability to prevent an unacceptable concentration of benzene from forming. The principal air flow ventilation path is included with a model representing the major features of the Tank 48 vapor space.

The present paper discusses the modeling approach and solution method to achieve the objective as mentioned above. 


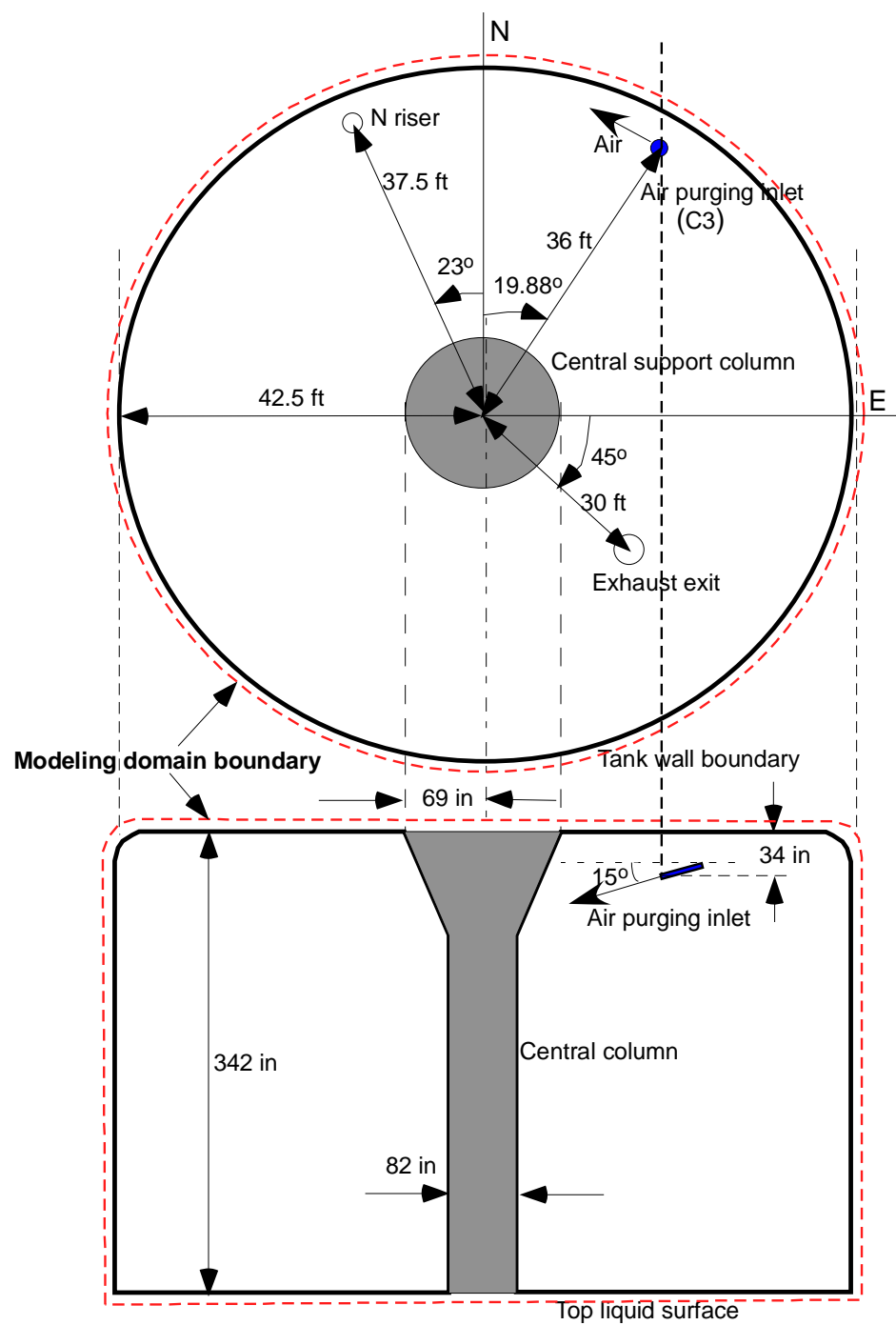

Figure 1. Tank geometry and modeling domain boundary used for the present analysis

\section{Modeling Approach and Solution Method}

A three-dimensional approach was taken to model the gas space of Tank 48 . The computational domain boundary used for the calculations is shown in Fig. 1. A finite volume CFD code, FLUENT ${ }^{\mathrm{TM}}$ [4], was used to create the prototypic geometry and to perform the analysis. A standard two-equation, $k-\varepsilon$ model, was used to estimate the gas turbulence since Reynolds numbers for typical $300 \mathrm{cfm}$ operation are in the range of 500,000 based on the inlet conditions of the 1-in nozzle. The governing equations to be solved are composed of one mass balance, three momentum equations for the threedimensional space, two turbulence equations, and species transport equation for benzene gas. The species transport equation includes mass diffusion and source terms for each of the gas species contained in the gas space.

Main assumptions for the modeling calculations were made as follows: 
- There is single exhaust location from the vapor space.

- There is single air injection location for a given calculation.

- The vapor space consists of air mixed with benzene gas evolved from the top surface of liquid zone.

- Benzene evolution rate from the bottom of the modeling domain is constant and uniform.

- Cooling coils in the vapor space have no impact on gas flow patterns.

- Air leakage into the vapor space is negligible.

- Temperature is constant, so thermally driven convection can be ignored.

- No chemical reactions during the benzene transport and mixing process.

- Benzene gas is a dilute mixture component, so the mass diffusion coefficient is independent of gas composition.

Target criteria for local benzene concentration in the vapor space will be provided by the customer organization. For the scoping calculations, 25\% of local benzene LFL, 1.37 benzene vol\%, is used as the target criterion. Based on the three-dimensional computation domain of Fig. 1 and the modeling assumptions, benzene mass fractions for the modeling cases are computed by the species transport equations in order to update the mixture properties under steady-state or transient operating conditions. Thus, the species balance equation is coupled with the momentum and turbulence equations of the bulk gas motion in the tank. The cases considered here and the material properties used for the calculations are shown in Table 1 and Table 2. All of the basic cases used a second order differencing scheme in order to minimize the numerical diffusion caused by the discretization.

The flow conditions for the vapor space during the air purging operation are corresponding to fully-turbulent flow since Reynolds numbers for typical $300 \mathrm{cfm}$ operation are in the range of 500,000 based on the inlet conditions of the 1-in nozzle. A standard two-equation turbulence model, the $\kappa-\varepsilon$ model [4], was used since the modeling results showed that the two-equation model predicts the flow evolution of turbulent flow in a large stagnant fluid domain with reasonable accuracy. The modeling results are compared with the literature results in Fig. 13. The benchmarking results demonstrate that the $k-\varepsilon$ turbulence model can accurately predict the flow patterns for ventilation air flow in a room within about $15 \%$ relative error.

The model is a full three-dimensional representation of the entire gas space to capture significant circulation phenomena related to the turbulent behavior of the gas flow. Air was used to simulate the gas in the vapor space. Although nitrogen is used as a purging gas instead of air, its flow pattern and mixing behavior are expected to be similar to those of air under the same operating conditions. Governing equations for the entire computational domain were solved by segregated solver in FLUENT for different cases in steady-state and transient simulation modes. They are the initial reference and the sensitivity cases as shown in Table 1 . The major material and physical properties used for the calculations are listed in Table 2. 


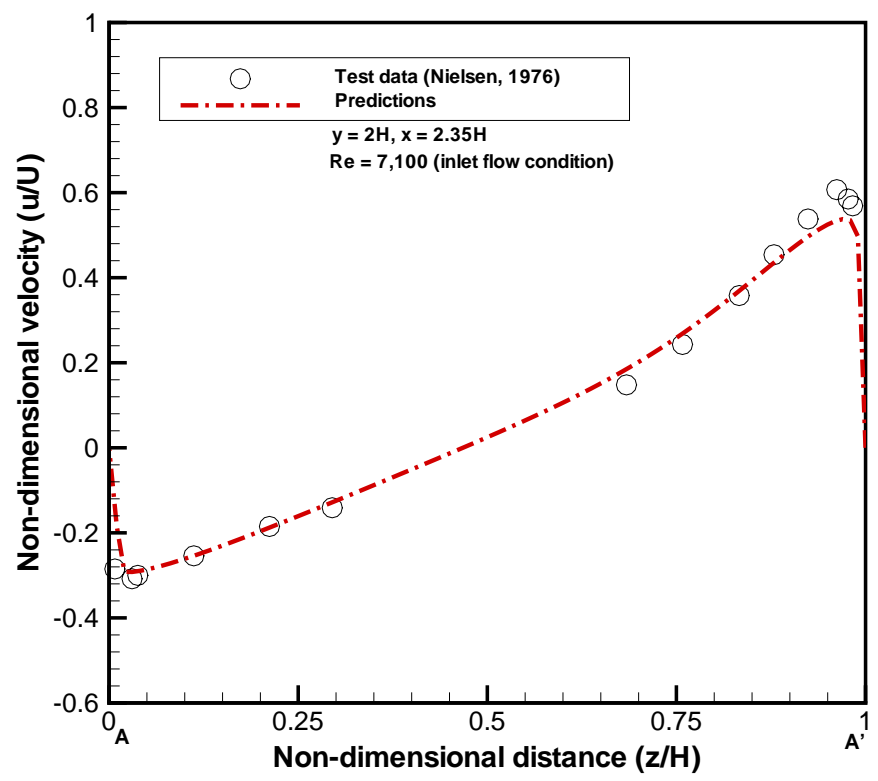

Figure 2. Benchmarking results against the literature data [5]

Table 1. Modeling conditions used for the sensitivity runs [1, 2]

\begin{tabular}{|c|c|c|c|c|c|}
\hline Cases & \multicolumn{2}{|c|}{ Purpose } & $\begin{array}{l}\text { Air inlet } \\
\text { location* } \\
\text { and size }\end{array}$ & $\begin{array}{c}\text { Air flowrate } \\
\text { at inlet } \\
\left(\mathrm{ft}^{3} / \mathrm{min}\right)\end{array}$ & $\begin{array}{c}\text { Benzene } \\
\text { generation } \\
\text { (gm/min) }\end{array}$ \\
\hline Reference & \multicolumn{2}{|c|}{ Initial test case } & C3(1-in dia.) & 300 & 400 \\
\hline Case-1 & \multicolumn{2}{|c|}{ Nominal mesh } & C3(1-in dia.) & 300 & 50 \\
\hline Case-1A & \multirow{3}{*}{$\begin{array}{l}\text { Numerical } \\
\text { sensitivity }\end{array}$} & Finer mesh & C3(1-in dia.) & 300 & 50 \\
\hline Case-1B & & $\begin{array}{l}\text { Numerical } \\
\text { differencing }\end{array}$ & C3(1-in dia.) & 300 & 50 \\
\hline Case-1C & & $\begin{array}{l}\text { Dynamic } \\
\text { response }\end{array}$ & C3(1-in dia.) & 300 & 50 \\
\hline Case-2 & \multicolumn{2}{|c|}{ Physical sensitivity } & C3(1-in dia.) & 150 & 50 \\
\hline Case-3 & \multicolumn{2}{|c|}{ Physical sensitivity } & N(6-in dia.) & 150 & 50 \\
\hline
\end{tabular}

Note: *See Fig. 1 for the location 
Table 2. Material properties and modeling conditions

\begin{tabular}{|c|c|}
\hline Parameters & Input data \\
\hline Air density & $1.225 \mathrm{~kg} / \mathrm{m}^{3}$ \\
\hline Benzene vapor density & $3.3 \mathrm{~kg} / \mathrm{m}^{3}$ \\
\hline Benzene molecular diffusion coefficient in air & $8.8 \times 10^{-6} \mathrm{~m}^{2} / \mathrm{sec}[1]$ \\
\hline Turbulent Schmidt number* & 0.7 \\
\hline
\end{tabular}

Note:*: Ratio of turbulent viscosity to mass diffusion

\section{Results and Discussions}

The present modeling calculations employed a three-dimensional CFD approach with two-equation turbulence model described in terms of turbulent dissipation and eddy diffusivity, referred to as $\kappa-\varepsilon$ model in the literature [4]. It assumed isothermal conditions for the gas medium so that buoyancy effect was not included. The computational domain is shown in Fig. 3.

The primary objective of the work was to estimate maximum benzene concentration under the potential operating conditions. The model actually computes benzene mass fractions. The benzene volume fraction is obtained from the computed mass fraction using a gas density ratio of benzene vapor to air of about 2.7. Graphical results are presented in Fig. 4. The benzene LFL concentration of 1.37 vol.\% corresponds to a mass fraction of 0.036 as shown in the figure.

The analysis considered four different cases of operating conditions as shown in Table 1. Before completing those runs, a series of test runs was conducted to evaluate the calculated sensitivity to the number of meshes, numerical differencing and transient system response to a sudden cessation of air flow at the inlet in order to establish the reliability of the solution method.

The model used two different meshes for the meshing sensitivity run, but the one-million mesh model was used for the initial test run. Two-million mesh nodes were also used for the evaluation of mesh sensitivity. The initial test case used $300 \mathrm{cfm}$ airflow through a 1-in inlet nozzle in the C3 riser and $400 \mathrm{gm} / \mathrm{min}$ benzene evolution from the liquid region. This is the reference case of Table 1 . The inlet velocity from $300 \mathrm{cfm}$ airflow through a 1-in nozzle is about $280 \mathrm{~m} / \mathrm{sec}$. Figure 5 shows velocity distributions and benzene mass fraction contours at the vertical plane crossing the central line A-A' under the referenced initial conditions. The results show a maximum benzene mass fraction of about 0.043 , corresponding to about 1.63 vol.\%. It is noted that when benzene is perfectly mixed with air inside the tank gas space under the steady-state operating conditions for the reference case, benzene volume percent is about 1.41. 


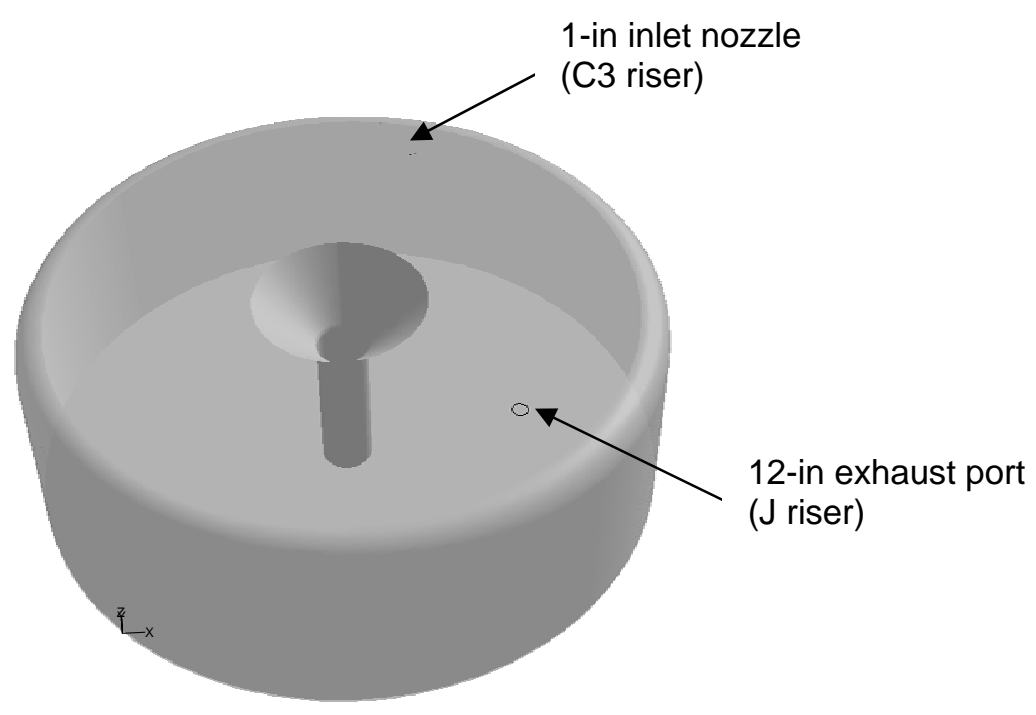

(Three-dimensional top view)

Figure 3. Computational domain as modeled for the calculations of benzene concentrations in the vapor space of Tank 48

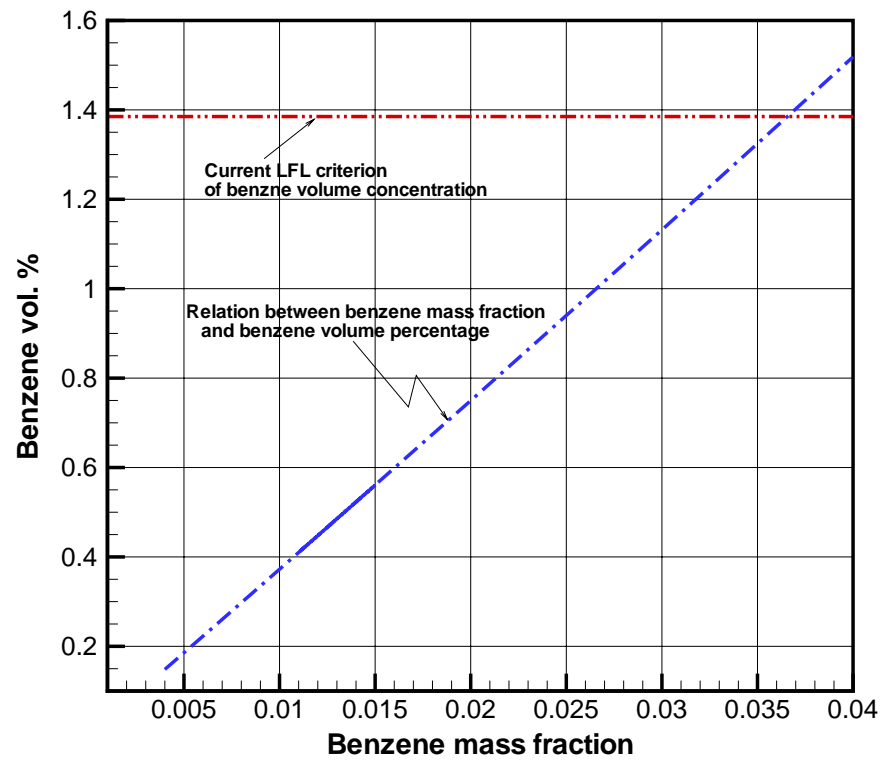

Figure 4. Benzene volume percentages for various benzene mass fractions 
The gas contained in the vapor space rotates counterclockwise around the central support column when the ventilation air inlet is located near the wall boundary and the air flow is injected into the vapor space azimuthally with a $15^{\circ}$ downward orientation toward the tank bottom. The calculation shows that gas movement near the wall boundary region is much stronger than the region near the central column. As shown in Fig. 5, the central region has higher benzene concentrations compared to the wall boundary region. It is also noted that the benzene concentration gradient over the entire region of the vapor space is very small. The level of benzene concentration is about $20 \%$ higher than the LFL value of 1.37 benzene vol\%. The calculation results show that the reference case does not support an acceptance criterion of $25 \% \mathrm{LFL}$, or 0.34 benzene vol.\%.

When the benzene evolution rate is reduced from $400 \mathrm{gm} / \mathrm{min}$ to the Case-1 value of 50 $\mathrm{gm} / \mathrm{min}$, the maximum benzene concentration shows a commensurate reduction of about $88 \%$. This result is to be expected because the driving flow, the air inlet, is the same in both calculations. It is noted that benzene concentration gradients over the entire region of the vapor space are consistently small because of the gas turbulence.

A series of sensitivity analyses was performed to evaluate the impact of the number of computational meshes, numerical differencing scheme, and dynamic system response on the numerical discretization error, referred to as numerical diffusion in the literature. About one million meshes were used for the nominal base cases such as Case-1, and about two million meshes were used for Case-1A with the finer mesh sizes to perform the sensitivity analysis. The calculations had identical operating conditions as shown in Table 1. The maximum mesh sizes for the two cases, Case-1 and Case-1A, were 9.6 and 6.5 inches, respectively. The sensitivity results show that the differences in velocity distributions between the coarser meshes of Case-1 and the finer meshes of Case-1A are negligibly small. Benzene concentration distributions at the central vertical and horizontal planes of the vapor space are about the same. The results demonstrated that the differences due to different mesh sizes are also negligibly small for the benzene concentration gradients. Based on these results, all the base cases used one million meshes.

Sensitivity results for different numerical differencing schemes were performed by using two different numerical approaches. The first case used the first-order numerical differencing scheme for the initial run, and then switched to a second-order scheme by restarting the problem from the final converged solution. The other approach used the second-order numerical scheme during the entire solution process. The calculations showed that no major difference resulted from using different differencing schemes. Maximum difference in benzene concentrations was about $1 \%$.

Qualitative dynamic behavior was examined by stopping the air inlet flow at the initial transient time beginning from the steady-state operating conditions of Case-1. This case corresponds to Case-1C as shown in Table 1. Dynamic responses of Case-1C are compared with the Case-1 results at 3 minutes transient time in terms of benzene concentrations in the tank vapor space as shown in Fig. 6. The results show that the transient responses are qualitatively correct, i.e., the flow slows down and appears to be stopping in the absence of a driving force. All the sensitivity calculations demonstrate that the current number of meshes and solution method used for the analysis provide reasonable numerical results.

When the inlet air flow is reduced from $300 \mathrm{scfm}$ to $150 \mathrm{scfm}$ as shown in Table 1, the inlet velocity magnitude is changed from about $280 \mathrm{~m} / \mathrm{sec}$ to $140 \mathrm{~m} / \mathrm{sec}$. For a benzene 
generation rate of $50 \mathrm{gm} / \mathrm{min}$ corresponding to Case-2, the maximum benzene concentration increases from $0.20 \mathrm{vol} \%$ to $0.41 \mathrm{vol} \%$. All the results show that benzene gas is well mixed by the purging air flow.

Lastly, when the inlet airflow of 150 scfm enters through the 6-in $\mathrm{N}$ riser instead of the 1in nozzle in the C3 riser (Case-3), benzene concentration gradients are significantly different. The results show that maximum benzene concentration reaches about 0.46 vol\%, compared to 0.41 vol\% of Case- 2 . It is also noted that the average benzene concentration difference between the maximum and minimum values for Case- 3 is about $150 \%$ of that seen in Case-2. Figure 7 compares the results between Case-2 and Case- 3 using the same color scale. The results show that Case- 3 has a more stratified benzene distribution than Case-2 because of less gas movement. It shows that the benzene concentration for Case-3 ranges from 0.46 to 0.36 vol\%. All the results for the cases considered here are summarized in Table 4. 

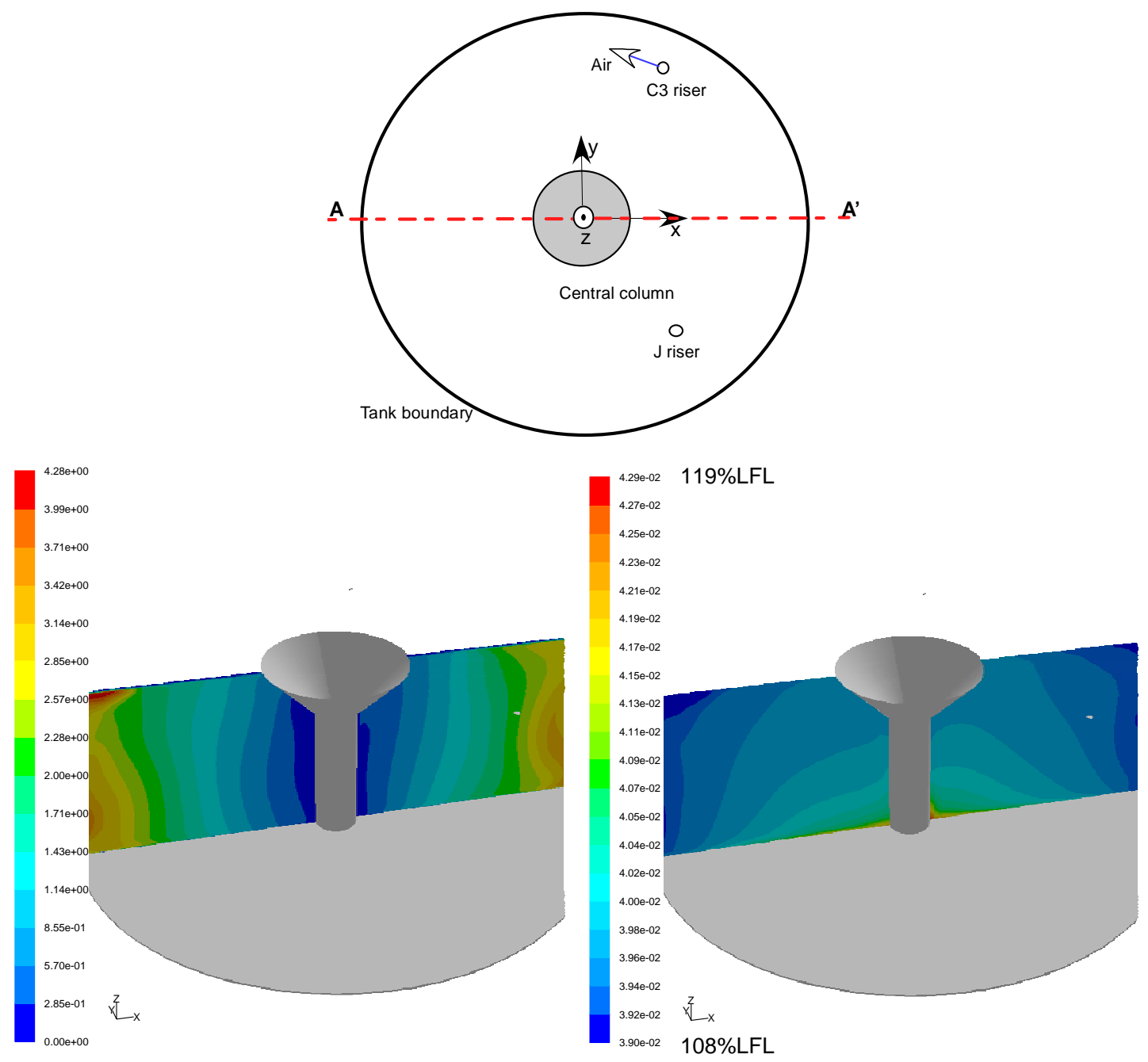

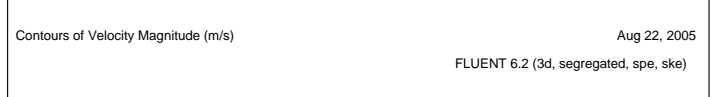

(Velocity distributions)

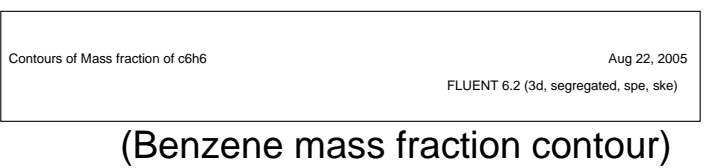

Figure 5. Velocity distributions and benzene mass fraction contours at the vertical plane crossing the central line A-A' under the referenced initial conditions 
$14.3 \%$ LFL

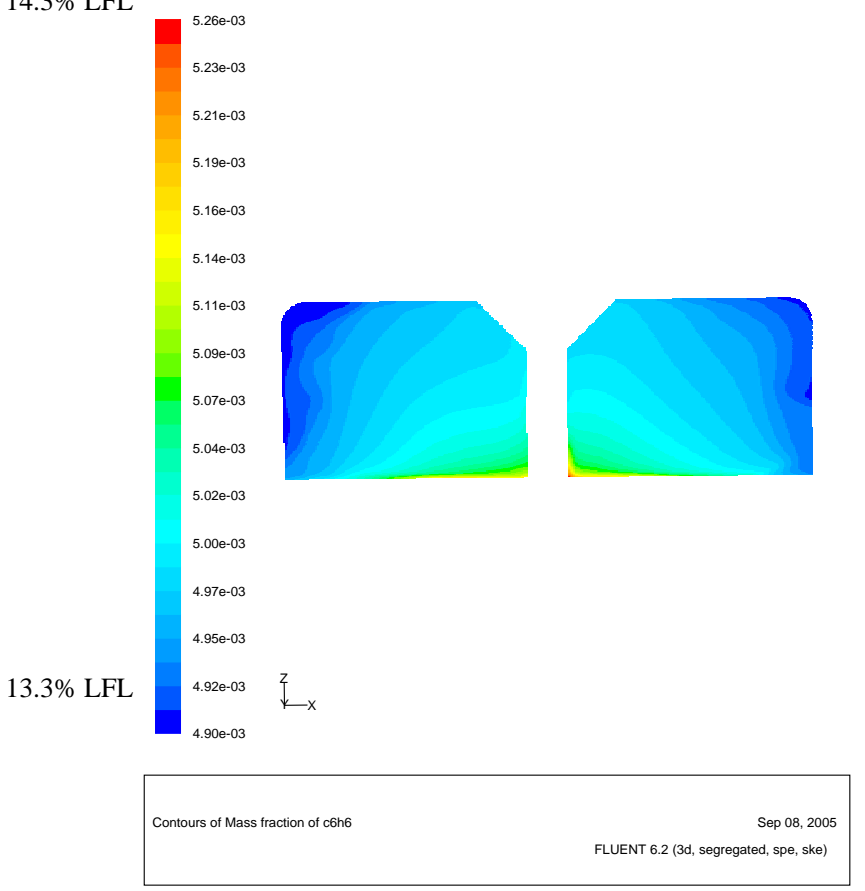

(Initial benzene concentrations established by the Case-1 conditions)

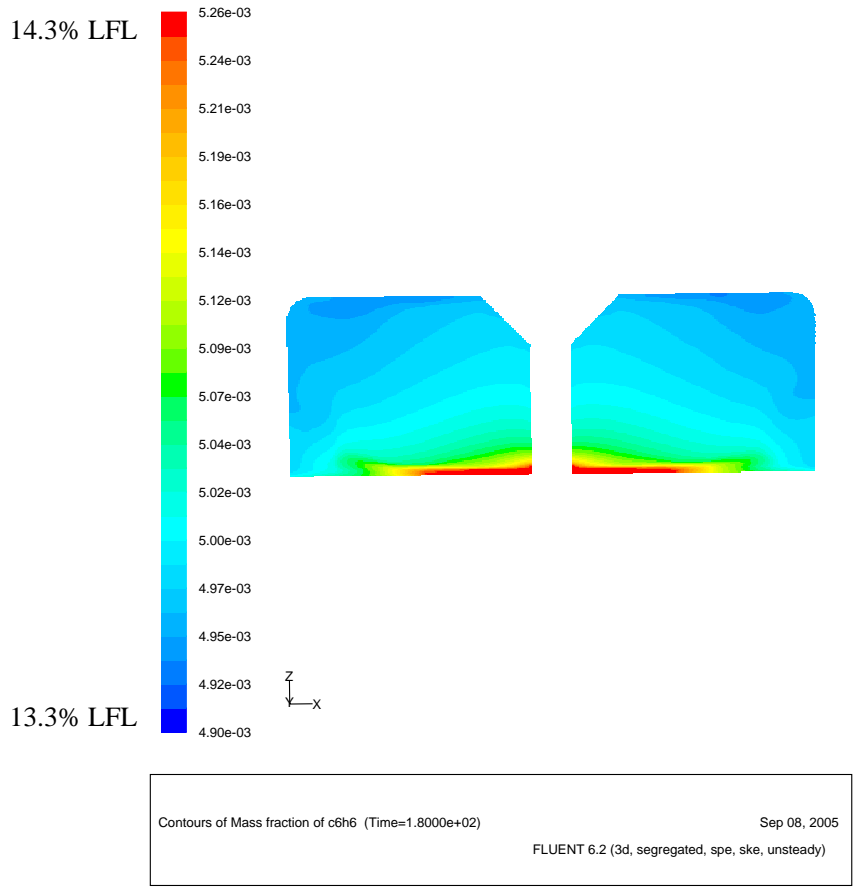

(Case-1C: Benzene concentrations at 3 min. of transient time after stopping the air purging of the Case- 1 conditions)

Figure 6. Transient responses of benzene concentrations of the tank vapor space to the zero inlet airflow conditions with the Case-1 results used as the initial conditions. 
$29.7 \%$ LFL
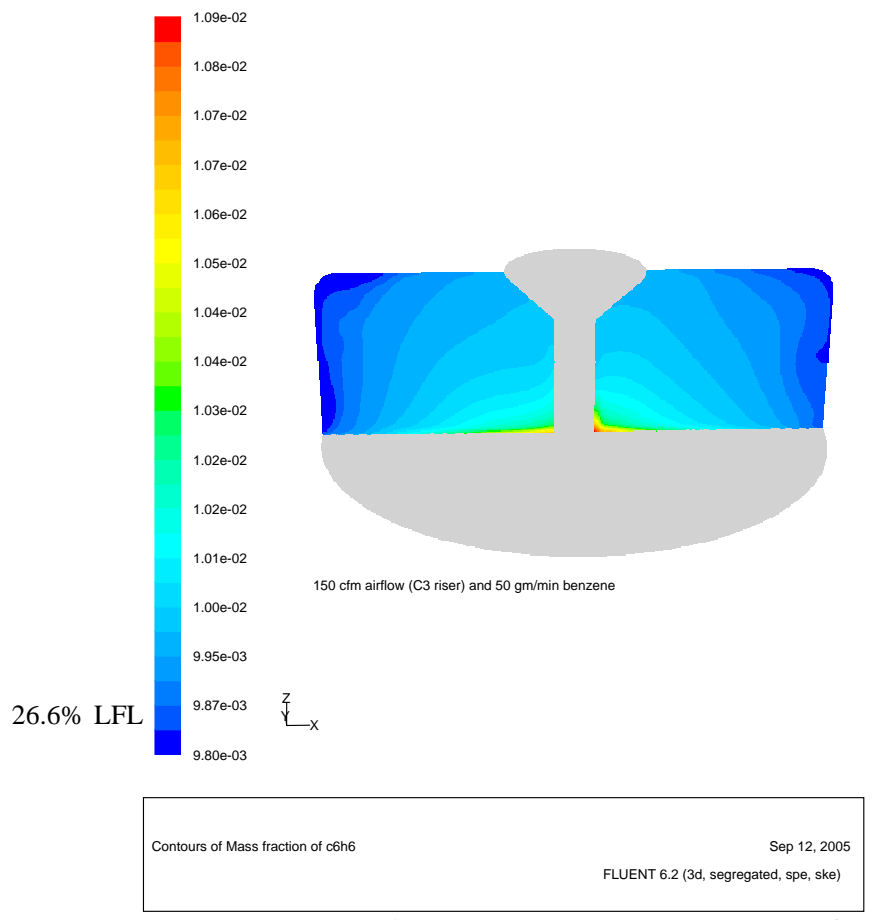

(Case-2: $150 \mathrm{cfm}$ airflow through C3 riser nozzle and $50 \mathrm{gm} / \mathrm{min}$. benzene)

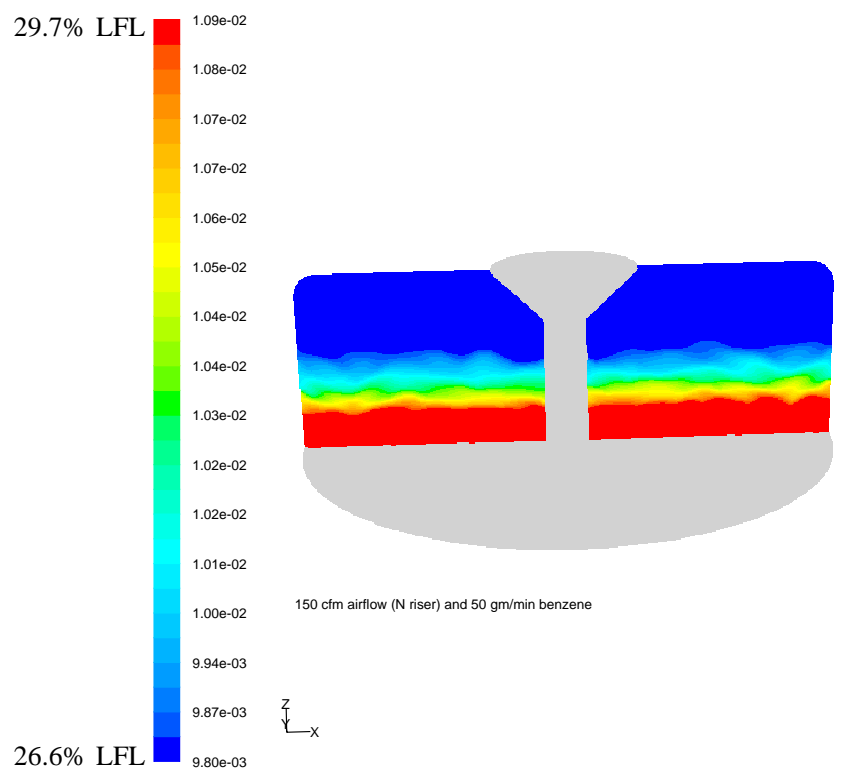

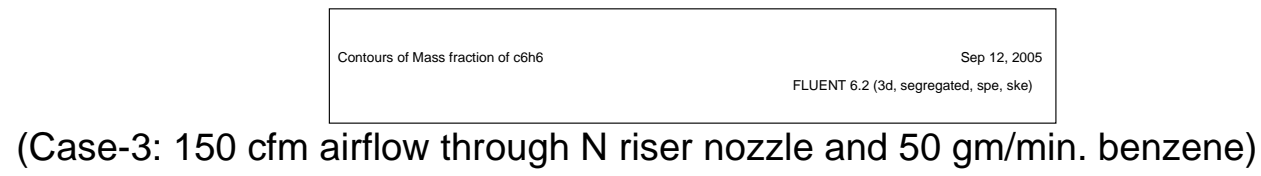

Figure 7. Comparison of benzene concentrations between the two cases under the same color scale 
Table 3. Summary of the calculated results for the cases considered in the present study

\begin{tabular}{|c|c|c|c|c|c|}
\hline Cases & $\begin{array}{c}\text { Air inlet } \\
\text { location } \\
\text { (size) }\end{array}$ & $\begin{array}{c}\text { Air flowrate } \\
\text { at inlet } \\
\left.\text { (ft }{ }^{3} / \mathrm{min}\right)\end{array}$ & $\begin{array}{c}\text { Benzene } \\
\text { generation } \\
\text { (gm/min) }\end{array}$ & $\begin{array}{l}\text { Max. benzene } \\
\text { concentration } \\
\text { (vol. \%) }\end{array}$ & $\begin{array}{c}\% \\
\text { benzene } \\
\text { LFL value* }\end{array}$ \\
\hline $\begin{array}{c}\text { Reference } \\
\text { (Initial case) }\end{array}$ & $\begin{array}{l}\text { C3 riser } \\
\text { (1 in) }\end{array}$ & 300 & 400 & 1.63 & 119 \\
\hline Case-1 & $\begin{array}{c}\text { C3 riser } \\
\text { (1 in) }\end{array}$ & 300 & 50 & 0.20 & 15 \\
\hline Case-1A & $\begin{array}{c}\text { C3 riser } \\
\text { (1 in) }\end{array}$ & 300 & 50 & 0.20 & 15 \\
\hline Case-2 & $\begin{array}{c}\text { C3 riser } \\
\text { (1 in) }\end{array}$ & 150 & 50 & 0.41 & 30 \\
\hline Case-3 & $\begin{array}{c}\mathrm{N} \text { riser } \\
(6 \text { in })\end{array}$ & 150 & 50 & 0.46 & 34 \\
\hline
\end{tabular}

Note:* \% LFL value is based on benzene LFL of 1.37 vol. $\%$ at $25^{\circ} \mathrm{C}$.

\section{Summary and Conclusions}

A computational fluid dynamics (CFD) method was developed to estimate maximum benzene concentration for the vapor space domain inside Tank 48 at SRS. The CFD model took a three-dimensional momentum-species transport coupled approach. The flow conditions for the operations are assumed to be fully turbulent since Reynolds numbers for typical operating conditions are in the range of 50,000 to 500,000 based on the inlet conditions of the air purging system. A standard two-equation turbulence model was used for this work. A series of sensitivity runs was performed to establish the numerical validity of the results.

The calculations included nominal boundary conditions for air inlet and exhaust, as well as benzene evolution from the tank liquid surface. Additional calculations included a reduced benzene evolution rate, reduced air inlet and exhaust flow, and a modified air inlet location. The calculations were based on prototypic tank geometry and nominal operating conditions. Detailed cases considered in the calculations are provided in Table 1.

The flow patterns in the vapor space demonstrate that with ventilation air entering the tank through a 1-in nozzle near the C3 riser, the benzene gas is fairly well mixed before leaving the tank via the exit riser. Mixing is not as good when air enters through the 6inch opening in the $\mathrm{N}$-riser with no nozzle to accelerate or direct the air. The modeling results showed that benzene concentrations were relatively low for all typical operating configurations and conditions. All the modeling calculations addressing sensitivity issues such as differencing options, mesh density, and transient performance demonstrated that the model could capture the necessary phenomena without introducing nonphysical behavior because of the numerical discretization. Therefore, 
refining and upgrading the present model is recommended for support of safety class calculations.

\section{References}

1. J. H. Perry, Chemical Engineer's Handbook, McGraw-Hill Book Company, Inc., $3^{\text {rd }}$ Edition, 1950.

2. FLUENT6, Fluent, Inc., 2005.

3. S. Y. Lee, R. A. Dimenna, D. B. Stefanko, R. A. Leishear, "Mixing in Large Scale Tanks - Part I, Flow Modeling of turbulent Mixing Jets," ASME Heat Transfer / Fluids Engineering Conference, Charlotte, N. C., July 11 - 15, 2004.

4. W. P. Jones and P. E. Launder, "The Prediction of Laminarization with a TwoEquation Model of Turbulence", Int. Journal of Heat and Mass Transfer, Vol. 15, pp. 301-314, 1972.

5. Nielsen, P. V., Restivo, A., and Whitelaw, J. H., "The Velocity Characteristics of Ventilated Rooms", J. of Fluids Engineering, Vol. 100, pp. 291-298, 1978. 